\title{
APORFIN SEBUAH ALKALOID DARI POHON HURU (Litsea cordata Sp) JACK (HOOK).F (LAURACEAE)
}

\author{
Budhiman Adi Setyawan \\ Fakultas Teknik UPN “Veteran” Jakarta \\ JL.RS.Fatmawati Pondok Labu Jakarta Selatan 12450 Telp.021-7762056 \\ e-mail : budhimanadisetyawan9@gmail.com
}

\begin{abstract}
Litsea cordata Jack (Hook).F is a high tree which grows in West Java. The Alkaloid constituents were isolated from methanol extract, by the usal acid-base extraction to produce a total alkaloid . The total alkaloid was separated into phenolic and non-phenolic fractions with the same way. Two alkaloids components isolated from the phenolic fraction suggested to be, tetrahydro-benzylisokuinolyne derivative and aporphine derivative base on spectroscopic data, UV and mass spectrum.
\end{abstract}

Keywords : Alkaloid, ultra violet, mass spectrum.

\section{PENDAHULUAN}

Indonesia sangat kaya akan flora dan fauna yang merupakan sumber daya organic . Kekayaaan ini umumnya belum dicatat,belum dikaji dan belum dipahami sehingga belum dapat dimanfaatkan secara optimal. Hal ini terbukti dengan ditemukannya senyawa-senyawa bahan alam baru yang unik dan langka seperti itebein,indonesiol dan furanoseskuiterpen yang berasal dari sumber daya organik yang terdapat di Indonesia (Achmad SA,2004).

Penelitian fitokimia tumbuhan khususnya tanaman yang ada di Indonesia telah dimulai oleh Gresshoff (1888). Pada saat itu kandungan kimia berbagai tanaman yang ada di Indonesia belum banyak diketahui dan umumnya penelitian tersebut ditujukan untuk survai kimia dan farmakologi yang sifatnya sederhana serta lebih mengarah kepada tanaman yang berkhasiat obat. Sekarang ini penelitian fitokimia berkembang Sangat pesat dengan cakupan pengkajian yang lebih luas. Tidak hanya terbatas pada pengkajian aktifitas dan khasiatnya saja akan tetapi lebih diarahan pada aspek kimianya . Alkaloid menjadi pembahasan yang lebih menarik karena adanya berbagai aktifitas fisiologis yang dimilikinya dan tentu akan memberikan sumbangan yang cukup berarti bagi dunia kedokteran masa kini ddan masa depan. Hal ini tercermin dari ratusan senyawa-senyawa alkaloid yang telah terbukti bersifat anestetik , analgetik, narkotik, stimulan sistem pernapasan, pelemas otot, insektisida dan sebagainya (Achmad SA,2004) .

Lauraceae merupakan salahsatu familia tanaman yang besar jumlahnya dan tersebar di daerah tropis, subtropics, di benua Amerika , Afrika dan Asia . Dari 31 genus yang termasuk familia lauraceae adalah Litsea.Litsea merupakan salahsatu dari 18 genus yang memiliki kandungan alkaloid (Kosterman AJGH, 1957). Salahsatu spesies Litsea yang tumbuh di sekitar gunung Tangkuban Parahu di Jawa Barat adalah Litsea cordata yang oleh masyarakat setempat kayunya digunakan sebagai bahan bangunan rumah, mebel perabot rumah tangga,kusen,jendela,pintu dan sebagainya . Adapun pengetahuan tentang senyawa kimia bahan alam yang dikandung oleh spesies tumbuhan tersebut belum pernah dilaporkan. Untuk itu perlu dilakukan penelitian tentang ilmu kimia dari spesies ini.

\section{Tinjauan Pustaka}

Litsea merupakan salahsatu genus tumbuhan yang termasuk kedalam familia Lauraceae. Ada sekitar 2500 spesies tumbuhan yang termasuk familia Lauraceae dan sekitar 474 spesias termasuk genus Litsea. Genus ini memiliki jumlah terbanyak setelah dan tersebar terutaman di daerah tropis seperti Asia, Australia dan Melanesia (Kostermans AJGH,1957) . Umumnya tumbuh sebagai pohon atau semak.

Menurut Gottlieb (1982) banyak manfaat 
yang diperoleh manusia dari tumbuhan familia Lauraceae ini seperti untuk perkayuan, bahan obat, rempah-rempah, minyak wangi dan sebagainya. Dimanfaatkannya Lauraceae dalam perkayuan karena kayunya berpenampilan baik, awet,tahan terhadap serangan bubuk sehingga banyak digunakan sebagai bahan ukiran (L.obtusuta), meubel (L.magnifolia) dan konstruksi bangunan(L.brachystachya,L.cassiaefolia, L.chinensis Lamk). Lauraceae yang dimanfaatkan sebagai bahan obat seperti pada spesies L.odrifera (sunda: trawas). Rebusan daun bersama kunyit dicampur gula dapat mengobati sariawan tropis pada tingkat permulaan. Rebusan daun bersama temulawak dapat mengobati penyakit empedu. Begitu juga pada spesies L.cassiaefolia daunnya digunakan sebagai obat penyakit kulit atau kudis dan kulit batang L.cubeba digunakan sebagai bahan pembuat parem. Lauraceae yang dipakai sebagai rempahrempah antara lain adalah spesies sassafras goesiuanum, kulit batangnya digunakan sebagai penyedap makanan dan salahsatu bagian dari jamu (Heyne,1977) sedangkan untuk minyak wangi digunakan spesies Aniba ducke Kosterm dari Brazilia dan Aniba rosaeodora dari Guyana . Heyne (1977) mengemukakan bahwa dari 478 spesies yang termasuk genus Litsea ada 22 spesies diantaranya terdapat di Indonesia yaitu :

\section{Litsea accedentoides \\ 2. Litsea amara \\ 3. Litsea angulata \\ 4. Litsea breachtachya \\ 5. Litsea cassiaefolia \\ 6. Litsea chinensis \\ 7. Litsea chrysocoma \\ 8. Litsea cubeba \\ 9. Litsea diversifolia \\ 10. Litsea ferruginea \\ 11. Litsea firma}

12. Litsea fulva
13.Litsea javanica
14.Litsea mapacea
15.Litsea odorifera
16. Litsea polyanta
17.Litsea resinosa
18.Litsea robusta
19.Litsea rumphii
20.Litsea sebifera
21.Litsea stikmanni
22.Litsea tomentosa

Pada tahun 1992 telah ditemukan spesies baru dari genus Litsea yaitu Litsea cordata (Kosterman AJGH, 1992) .

Adapun klasifikasi spesies tumbuhan ini yaitu :

$\begin{array}{lll}\text { Divisi } & : & \text { Spermatophyta } \\ \text { Sub divisi } & : & \text { Angiospermae } \\ \text { Kelas } & : & \text { Dicotyledonae } \\ \text { Ordo } & : & \text { Polycarpicae } \\ \text { Familia } & : & \text { Lauraceae } \\ \text { Genus } & : & \text { Litsea } \\ \text { Spesies } & : & \text { Litsea cordata }\end{array}$

Sampai saat ini penelitian terhadap kandungan kimia dari spesies tumbuhan Litsea cordata belum pernah dilaporkan dalam literatur. Dari spesies-spesies didalam genus Litsea yang telah dilaporkan mengandung senyawa alkaloid melalui teknik isolasi dikelompokkan kedalam lima struktur molekul umum yaitu :

1. Aporfin

2. Oksoaporfin

3. Tetrahidrobenzilisokuinolin

4. Morfinandienon

5. Fenantren

Alkaloid yang banyak ditemukan didalam genus Litsea umumnya berasal dari jenis struktur aporfin.

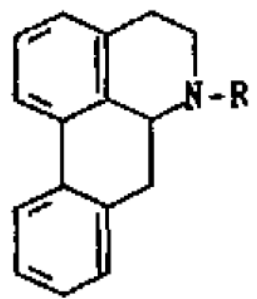

Gambar 1. Struktur Molekul Aporfin

\section{Ekstraksi dan Kromatografi}

Percobaan pertama adalah menguji secara kualitatif apakah ada alkaloid atau tidak didalam sampel uji dari kulit batang pohon huru (Litsea cordata) dengan menggunakan 3(tiga) jenis reagent yaitu Reagent Meyer,Wagner dan Dragendorff dengan mengikuti metoda Culvenor dan Fitzgerald. Caranya adalah sbb.: Sekitar 5 gram sampel segar dipotong kecil-kecil lalu ditumbuk halus menggunakan mortar. Kemudian dibasahi dengan $5 \mathrm{ml}$ kloroform yang mengandung sedikit amoniak. Selanjutnya ditambah lagi $10 \mathrm{ml}$ kloroform beramoniak sambil diaduk-aduk dan disaring kedalam tabung reaksi sehingga menghasilkan ekstrak kloroform . Selanjutnya, 10 tetes asam sulfat 5\% dimasukkan kedalam tabung reaksi dan dikocok. Terjadi dua lapisan yang salahsatunya adalah lapisan asam . Lapisan asam dipisahkan dan dimasukkan kedalam tabung reaksi lain . Kemudian tambahkan 3 tetes reagent untuk uji alkaloid . Hasil yang positip ditunjukkan dengan terjadinya kekeruhan yang ditandai dengan (+) sampai pembentukan endapan yang banyak dengan (++++).Sebagai pembanding,digunakan daun tapak dara (Vinca rosea sp.) dari Kebun Raya Bogoryang diketahui mengandung alkaloid. Data yang diperoleh dari hasil pengujian tersebut yaitu Reagent Meyer (++), Wagner (++) dan Dragendorf (++). 
Percobaan yang kedua adalah pemisahan alkaloid total. Mula-mula kulit batang pohon huru (Litsea cordata) dibersihkan dari kotoran yang menempel menggunakan sikat ijuk lalu dicuci bersih.Kulit batang yang sudah bersih dirajang sampai menjadi bubuk kasar. Lalu dikeringkan sampai beratnya tetap.

Bubuk kasar kulit batang $(8 \mathrm{~kg})$ dimaserasi (direndam) didalam n-heksan teknis (20 l) selama 24 jam . Residu yang diperoleh dimaserasi lagi didalam metanol teknis (20 l) . Ekstrak metanol yang diperoleh dipekatkan pada tekanan rendah sampai terbentuk ekstrak metanol yang hampir kering (400g).Kemudian diekstraksi dengan larutan asam sitrat 5\% (10 1). Fraksi asam dicuci dengan eter sampai lapisan itu tidak berwarna. Lapisan asam dibasakan dengan amoniak sampai pH 8-9. Endapan yang terbentuk disaring lalu diekstraksi dengan kloroform teknis (5 1). Ekstraksi diulang beberapa kali sampai ekstrak yang diperoleh menunjukkan hasil negatip terhadap uji alkaloid. Proses yang sama dilakukan pula terhadap filtrat fraksi basa.Kloroform yang didapat dari kedua fraksi tersebut digabungkan kemudian dicuci dengan air didalam corong pisah sampai air cucian bersifat netral terhadap kertas lakmus. Lalu lapisan kloroform dikeringkan dengan magnesium sulfat anhidrat dan diuapkan pada tekanan rendah sampai kering . Akhirnya diperoleh alkaloid total (fenolik dan non-fenolik) sebanyak 6,0 gram. Pengerjaan selanjutnya adalah memisahkan alkaloid fenolik dengan non-fenolik.Pertama kali alkaloid total dilarutkan dalam kloroform p.a kemudian diekstraksi dengan larutan $\mathrm{NaOH} 5 \%$. Fraksi basanya diasamkan dengan $\mathrm{NH} 4 \mathrm{Cl}$ sampai $\mathrm{pH}$ 89. Endapan yang terbentuk dilarutkan dalam kloroform. Kedua fraksi digabungkan. Lalu dicuci dengan air sampai air cucian bersifat netral terhadap kertas lakmus. Kemudian dikeringkan dengan MgSO4 anhidrat selanjutnya diuapkan pada tekanan rendah menghasilkan fraksi alkaloid fenolik 3,0 gram . Terhadap fraksi fenolik ini dilakukan pemisahan dari komponen-komponennya melalui kromatografi secara kromatotron. Prinsipnya sampel alkaloid fenolik (200 mg) diletakkan pada plat yang mengandung silika gel 60 PF 254 (45 g). Lalu dielusi dengan diklorometan ( $\mathrm{CH}_{2} \mathrm{Cl}_{2}$ ), campuran metanol- $\mathrm{CH}_{2} \mathrm{Cl}_{2}$ yang meningkat kepolarannya dan menghasilkan beberapa fraksi yang mengandung komponen alkaloid fenolik yang relatip murni. Untuk menda- patkan komponen yang cukup murni perlu dilakukan dua kali lagi proses kromatografi dengan cara kromatotron sehingga diperoleh dua fraksi alkaloid fenolik (F1 dan F2) yang terelusi oleh campuran 50\% metanol dalam aseton.F1 yang diperoleh cukup murni sedangkan F2 perlu dilakukan dua kali kromatografi dengan pengelusi $30 \%$ metanol dalam $\mathrm{CH} 2 \mathrm{Cl} 2$.

Percobaan yang ketiga adalah proses karakterisasi terhadap F1 (Alkaloid A) dan F2 (Alkaloid B). Ada 4 (empat) tahap pengerjaan yaitu : 1.Pemeriksaan kromatografi lapis tipis.

Pemeriksaan lapis tipis menggunakan kromatogram silika gel 60 GF (Al2O3 GF 254) jenis DC Alufolen dengan ukuran $20 \times 20 \mathrm{~cm}$ buatan Merck. Sampel dilarutkan didalam pelarut yang sesuai dan dielusi dengan sistem naik. Noda bercak pada kromatogram akan tampak dibawah sinar ultra violet atau penyemprotan dengan reagent Dragendorff. Analaisis kromatografi lapis tipis terhadap F1 (Alkaloid A) dan F2 (Alkaloid B) memberikan harga sbb. :

\begin{tabular}{|c|c|c|c|}
\hline \multicolumn{2}{|r|}{$F_{1}($ Alkaloid $A)$} & \multicolumn{2}{|r|}{$\mathrm{F}_{2}$ (Alkaloid B) } \\
\hline $\mathrm{Rf}$ & Eluen & $\mathrm{Rf}$ & Eluen \\
\hline 0,32 & $\left(\mathrm{MeOH}: \mathrm{CHCl}_{3}=3: 7\right)$ & 0,46 & $\left(\mathrm{MeOH}: \mathrm{CHCl}_{3}=3: 7\right)$ \\
\hline 0,36 & $\left(\mathrm{MeOH}: \mathrm{CH}_{2} \mathrm{Cl}_{2}=3: 7\right)$ & 0,46 & $\left(\mathrm{MeOH}: \mathrm{CH}_{3} \mathrm{Cl}=3: 7\right)$ \\
\hline 0,31 & (MeOH:Aseton=3:7) & 0,35 & (MeOH: $\left.\mathrm{C}_{6} \mathrm{H}_{6}=1: 1\right)$ \\
\hline 0,31 & (MeOH:Aseton=1:1) & 0,38 & (MeOH:Aseton=1:1) \\
\hline 0,20 & (EtOH:Aseton=1:1) & & \\
\hline
\end{tabular}

\section{Penentuan titik leleh.}

Penentuan titik leleh menggunakan alat Fisher John Melting Point Apparatus . Hasil pengamatan dinyakan dalam derajat Celcius (OC),tidak dikoreksi.Prinsip kerjanya yaitu sedikit kristal diapit oleh dua plat kaca (deck glass) lalu diletakkan diatas plat logam dan dipanaskan dengan energi listrik . Melalui termometer yang terpasang pada plat logam maka laju kenaikan suhu bisa diikuti, sedangkan perubahan wujud kristal bisa diamati dibawah kaca pembesar yang disorot dengan lampu.Kecepatan kenaikan suhu dapat diatur $0,5-1,0{ }^{\circ} \mathrm{C}$ permenit. Pembacaan titik leleh dilakukan pada saat mulai dan habis meleleh. F1 (Alkaloid A) berupa padatan amorf, berwarna putih kemerahan dengan titik leleh 68-70 oC. F2 (Alkaloid B) berupa padatan amorf , berwarna putih kekuningan dengan titik leleh 105-107 oC.

\section{Pemeriksaan spektroskopi ultra violet.}

Pemeriksaan spektroskopi ultra violet menggunakan alat Spektrofotometer UV-VIS Shimidzu model UV-210 A. Prinsip kerjanya yaitu 
sampel sebanyak $0,0001 \mathrm{~g}$ dilarutkan dalam 10 $\mathrm{ml}$ etanol didalam labu ukur. Pada penentuan efek batokromik, kedalam larutan sampel perlu ditambahkan 1 tetes larutan $\mathrm{NaOH}$ 5\% sedangkan untuk efek hipsokromik ditentukan dengan melarutkan sedikit sampel dalam metanol yang ditambahkan 1 tetes larutan $\mathrm{HCl}$ 5\%. Dari pemeriksaan spektroskopi ultra violet terhadap F1 (Alkaloid A) dan F2 (Alkloid B) memberikan data sbb. :

Tabel 1. Data Spektrum UV dari $\mathrm{F}_{1}$ (Alkaloid A)
\begin{tabular}{|c|c|c|c|c|c|}
\hline Eluen & $\lambda_{\text {mals. }}$ & $n m(\log \epsilon)$ & Eluen & $\lambda_{\text {min. }}$ & $n$ m $(\log \epsilon)$ \\
\hline $\mathrm{MeOH}$ & 232,0 & 3,618 & $\mathrm{MeOH}$ & 257,0 & 3,040 \\
\hline $\mathrm{MeOH}$ & 284,0 & 3,438 & $\mathrm{MeOH}$ & 293,0 & 3,352 \\
\hline $\mathrm{MeOH}+\mathrm{NaOH}$ & 230,0 & 3,621 & $\mathrm{MeOH}+\mathrm{NaOH}$ & 270,0 & 3,045 \\
\hline $\mathrm{MeOH}+\mathrm{NaOH}$ & 327,0 & 3,574 & $\mathrm{MeOH}+\mathrm{HCl}$ & 260,0 & 3,024 \\
\hline $\mathrm{MeOH}+\mathrm{HCl}$ & 233,0 & 3,618 & $\mathrm{MeOH}+\mathrm{HCl}$ & 294,0 & 3,355 \\
\hline $\mathrm{MeOH}+\mathrm{HCl}$ & 285,0 & 3,423 & - & - & - \\
\hline $\mathrm{MeOH}+\mathrm{HCl}$ & 306,0 & 3,436 & - & - & - \\
\hline
\end{tabular}

Tabel 2. Data Spektrum UV dari $\mathrm{F}_{2}$ (Alkaloid B)
\begin{tabular}{|c|c|c|c|c|c|}
\hline Eluen & $\lambda_{\text {rals. }}$ & $\operatorname{nm}(\log \epsilon)$ & Eluen & $\lambda_{\text {min. }}$ & $\operatorname{nm}(\log \epsilon)$ \\
\hline $\mathrm{MeOH}$ & 238,0 & 3,668 & $\mathrm{MeOH}$ & 256,0 & 3,174 \\
\hline $\mathrm{MeOH}$ & 284,0 & 3,669 & $\mathrm{MeOH}$ & - & - \\
\hline $\mathrm{MeOH}+\mathrm{NaOH}$ & 245,0 & 3,702 & $\mathrm{MeOH}+\mathrm{NaOH}$ & 268,5 & 3,508 \\
\hline $\mathrm{MeOH}+\mathrm{NaOH}$ & 292,0 & 3,668 & $\mathrm{MeOH}+\mathrm{HCl}$ & 257,0 & 3,182 \\
\hline $\mathrm{MeOH}+\mathrm{HCl}$ & 241,5 & 3,667 & - & - & - \\
\hline $\mathrm{MeOH}+\mathrm{HCl}$ & 284,0 & 3,670 & - & - & - \\
\hline
\end{tabular}

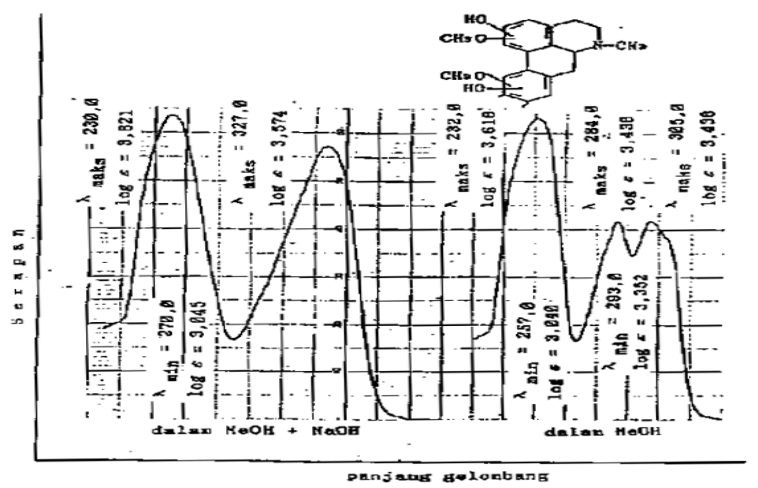

Gambar 2. Spektrum serapan Ultra violet dari F1 (Alkaloid A)
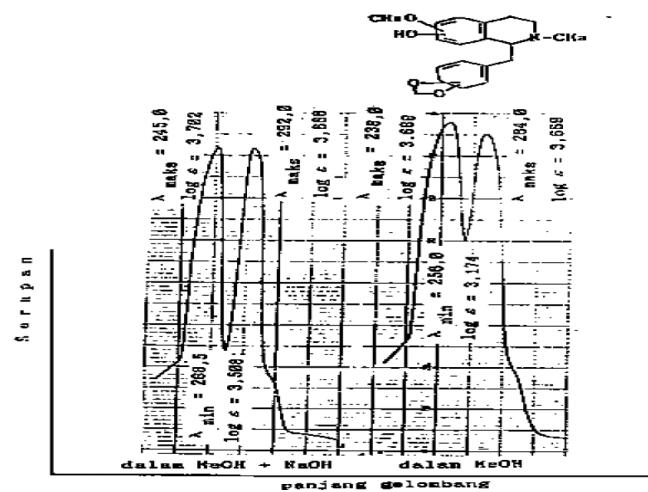

Gambar 3. Spektrum Serapan Ultra violet dari F2 (Alkaloid B)

\section{Pemeriksaan Spektroskopi massa.}

Pemeriksaan spektroskopi massa menggunakan alat Shimidzu GC-MS QP 1000 A. Persiapan bahan dan pembuatan spectrum dilakukan oleh operator. Untuk sampel F1 (Alkaloid A) memberi- kan harga m/z : M+ 327 (base), 326,310,296, 283, 252 (Gambar 4). Sedangkan sampel F2 (Alkaloid B) memberikan harga $\mathrm{m} / \mathrm{z}: 327(\mathrm{M}, 0,3), 206$ $(0,6), 192(100,0), 177(26,1)$ (Gambar 5)
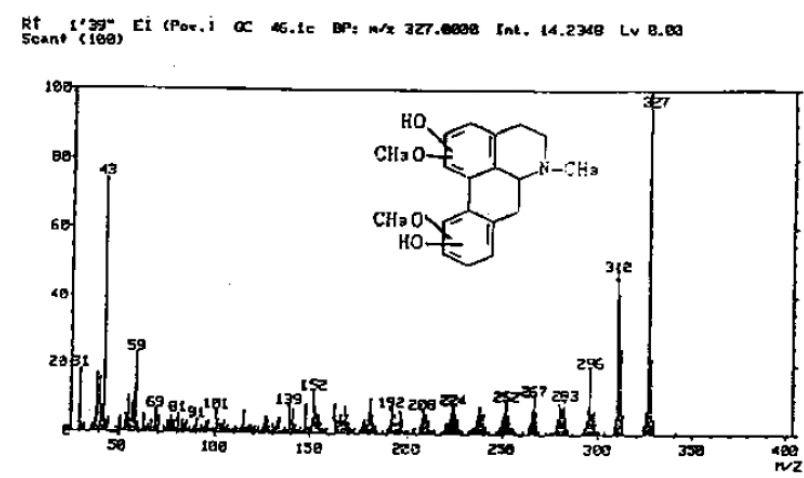

Gambar 4. Spektrum massa sampel F1 (Alkaloid A)

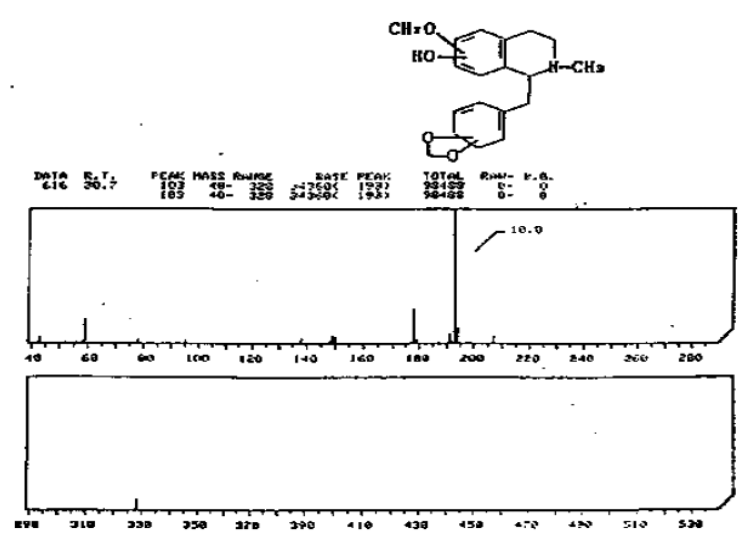

Gambar 5. Spektrum massa sampel F2 (Alkaloid B)

\section{Elusidasi/Penentuan Struktur F1 (Alkaloid A) dan F2 (Alkaloid B)}

Hasil pengukuran spektroskopi massa terhadap sampel F1 (Alkaloid A) memberikan spektrum massa dengan puncak ion molekul pada $\mathrm{m} / \mathrm{z}=327,0$ sesuai dengan rumus molekul $\mathrm{C}_{19} \mathrm{H}_{21} \mathrm{O}_{4} \mathrm{~N}$ (berat molekul teoritik $=327,2133$ ) dan nilai DBE (Double bond equivalent) 10. Ion fragmen yang muncul pada m/z 152 dan m/z 165 merupakan ciri khas adanya aporfin . Walaupun hal ini sukar diterangkan namun kenyataan seperti yang dilaporkan oleh beberapa peneliti terdahulu, kedua puncak ini selalu muncul pada spectrum massa semua senyawa aporfin dengan pola oksigenasi yang bermacam-macam (M.Shama, 1984 dan AH. Jackson,1986).Puncak-puncak ion fragmen lain pada m/z 326 menunjukkan lepasnya gugus $\mathrm{OH}$ radikal, m/z 296 menunjukkan lepasnya gugus -OCH3 radikal, m/z 283 menunjukkan lepasnya atom $\mathrm{H}$ radikal yang diikuti dengan lepasnya gugus $-\mathrm{CH}=\mathrm{N}-\mathrm{CH} 3$.

Adanya tiga puncak serapan UV pada £maks., 
nm $(\log \mathrm{E}): 232,0(3,618), 284(3,438), 305$ $(3,438)$ (Gambar 1) menunjukkan adanya cincin aromatik (sistim konjugasi yang panjang). Hal ini berarti sampel F1 (Alkaloid A) berasal dari turunan aporfin. Menurut Sangster (1985) pola spektrum dengan tiga puncak serapan utama pada panjang gelombang sekitar 200, 262 dan 303-310 nm menunjukkan adanya serapan alkaloid turunan aporfin. Shama dalam buku "The Alkaloid" vol. IX (RHF Manske,1987) menyatakan bahwa alkaloid aporfin dengan serapan sekitar panjang gelombang $(\mathfrak{f})=200,305 \mathrm{~nm}$ (intensitas hampir sama) dan $220 \mathrm{~nm}$ (intensitas lebih tinggi) mempunyai pola substitusi 1,2, 9, 10. Keberadaan gugus $-\mathrm{OH}$ pada cincin benzena dari kerangka molekul aporfin, didukung oleh dua puncak serapan UV pada £maks, nm $(\log \mathrm{E})=230,0(3,621), 327,0$ $(3,574)$ yang menunjukka adanya efek batokromik setelah penambahan $\mathrm{NaOH}$.

Hasil pengukuran spektroskopi masa terhadap F2 (Alkaloid B) memberikan spektrum massa seperti terlihat pada gambar 5. Puncak ion molekul m/z 327,0 sesuai dengan rumus molekul $\mathrm{C}_{19} \mathrm{H}_{21} \mathrm{O}_{4} \mathrm{~N}$ (berat molekul teoritik adalah 327,2133 . Nilai $\mathrm{DBE}=10$. Puncak ion fragmen yang muncul pada $\mathrm{m} / \mathrm{z}=206$ menunjukkan lepasnya gugus $-\mathrm{C}_{7} \mathrm{H}_{5} \mathrm{O}_{2}$ radikal, $\mathrm{m} / \mathrm{z}=192$ menunjukkan lepasnya gugus $-\mathrm{C}_{8} \mathrm{H}_{7} \mathrm{O}_{2}$ radikal, $\mathrm{m} / \mathrm{z}=177$ menunjukkan lepasnya gugus $-\mathrm{C}_{8} \mathrm{H}_{7} \mathrm{O}_{2}$ radikal yang diikuti lepasnya gugus $\mathrm{CH}_{3}+$. Adanya dua puncak serapan UV pada £maks. , $n m(\log \mathrm{E})=238,0(3,668), 284,0(3,669)$ menunjukkan bahwa F2 (Alkaloid B) berasal dari turunan tetrahidro-benzil-isokuinolin. Keberadaan gugus -OH pada cincin benzene dari kerangka molekul tetrahidro-benzil-isokuinolin didukung oleh terjadinya pergeseran batokromik dalam spektrum serapan UV setelah ditambahkan $\mathrm{NaOH}$.

\section{PENUTUP}

Berdasarkan hasil penelitian yang telah dilakukan dapat disimpulkan bahwa pada fraksi basa metanol, kulit batang Litsea cordata sp telah berhasil diisolasi dua senyawa alkaloid masingmasing disarankan sebagai turunan aporfin dan tetrahidro-benzil-isokuinolin . Alkaloid turunan aporfin merupakan padatan amorf , berwarna putih kemerah-merahan denngan titik leleh 105-107o $\mathrm{C}$, sedangkan turunan tetrahidro-benzil-isokuinolin merupakan padatan amorf ,berwarna putih kekuning-kuningan dengan titik leleh 68-700 C.
Struktur kedua alkaloid ini belum dapat ditentukan karena harus menunggu data NMR (Nucleic Magnetic Resonance) dari Jepang.

\section{DAFTAR PUSTAKA}

Achmad,SA, 2001,"Ilmu kimia bahan alam dan prospek pengembangannya dalam eraq industrialisasi”, Makalah disampaikan pada seminar di Universitas Andalas , Padang, 11 halaman.

Achmad,SA, 2001,"Isolasi dan identifikasi asam suatu seskuiterpen baru dari Neolitsea cassiaefolia”, Makalah pada Workshop on research in essensial oil 12-14 Maret di Surabaya,,13 halaman

Bick,IRC and Wannel Sinchai ,2008, "Alkaloid of the Lauraceae”, Heterocycles 9 (7), 90341.

Gottlieb,OR , 2002, "Chemosystematic of the Lauraceae”, Phytochemistry 11, 1537-70.

Harborne,JB and BL Turner 2004, Alkaloid and other plant toxins,plant chemosystema-tics", Academic Press, London , 75-127.

Heyne K , 2007, "Tumbuhan berguna Indonesia” Jilid II, Terjemahan Balai itbang Kehutanan, Jakarta.

Kosterman AJGH,1987, "Lauraceae”, 7ed Chemistry for Res.Indonesia 57, 1-63.

Maolana Syah,Y,1999, "Beberapa alkaloid dari kulit batang Persea rimosa (Bl.)”, Tesis,ITB, Bandung.

Shama,M and SY.Yao, 2001, "The Ultra Violet Spectra of Phenolic Aphorphines in Basic Solution” , J. Org.Chem., 36 (21) , 253-4.

Sangster,AW and Kenneth L.Stuart,1995,"Ultra violet spectra of Alkaloid", Chemical Review,65,69-84. 